\title{
Antenatal ultrasonography to detect fetal renal abnormalities: a prospective screening programme
}

\author{
L N Livera, D S K Brookfield, J A Egginton, J M Hawnaur
}

\begin{abstract}
Objective-To evaluate screening for abnormalities of the fetal renal tract by ultrasonography and to determine the incidence of such abnormalities in a population.
\end{abstract}

Design-A 12 month prospective population study. Follow up of infants to between 9 and 18 months.

Setting-A district general hospital.

Participants -6292 Pregnant women reaching 28 weeks' gestation within the study period.

Interventions-Antenatal ultrasound scanning was offered to all of the women. Babies in whom an abnormality of the renal tract had been detected antenatally underwent ultrasound scanning at the end of the first week. If the abnormality was confirmed contrast radiography was performed.

End point-Confirmation of suspected renal abnormality by postnatal investigations. Detection of abnormality in children thought to be normal antenatally.

Measurements and main results - of the 92 babies who had abnormal antenatal scans, 42 had abnormalities confirmed postnatally. Four of them died and 21 had had or were awaiting an operation at 18 months' follow up. Seven children had renal abnormalities that were missed antenatally. The incidence of abnormalities detected by screening antenatally was $0.65 \%$, and the overall incidence at 18 months' follow up was $0.76 \%$.

Conclusions-The incidence of structural renal abnormalities in babies is higher than reported previously. Antenatal ultrasonography is an effective way of detecting such abnormalities.

\section{Introduction}

Routine antenatal ultrasonography is being used increasingly to detect abnormalities of the fetal urinary tract, some of which are important and may benefit from early diagnosis and treatment. Antenatal scanning indicates abnormalities of the urinary tract reliably in both selected and unselected groups, although its diagnostic accuracy is not always clear. ${ }^{12}$ The incidence of fetal uropathy has been reported recently to vary from $0 \cdot 14 \%$ to $0 \cdot 39 \% .{ }^{3}$ Ring and Zobel suggested that, although many abnormalities of the urinary tract can be diagnosed prenatally, a high proportion will not be found until after infection of the urinary tract during infancy. ${ }^{4}$ The value of early diagnosis of some renal abnormalities is debatable, particularly as the natural course is unknown for some types of lesions. For other lesions, however, early diagnosis and postnatal treatment undoubtedly minimises renal damage. ${ }^{15}$

Fetal abnormalities of the renal tract can be screened for specifically. The optimum time for screening to achieve maximum pick up has not been ascertained. During a screening programme for fetal malformation in Sweden only $9 \%$ of renal abnormalities were detected by 17 weeks' gestation, but $91 \%$ were detected by 33 weeks. ${ }^{5}$ In a group with non-lethal abnormalities the abnormalities were detected in only a few cases before 24 weeks. ${ }^{6}$
We implemented a prospective antenatal screening programme to ascertain the incidence of renal tract disease by ultrasonography and its outcome in a specific population and evaluated the sensitivity and specificity of the programme.

\section{Patients and methods}

Between November 1986 and October 1987 this hospital served a district population of about 463000 with little cross boundary flow. Over $99 \%$ of deliveries took place in the hospital, either in the consultant or the general practitioner unit, giving an ideal population for the study. All pregnant women registered at the hospital during this time were offered scans at 28 weeks' gestation plus or minus two weeks. The fetal urinary tract was evaluated and fetal growth, placental site, and any fetal abnormality assessed. Subsequent scans were obtained when indicated to observe the progression of dilatation of the urinary tract or for obstetric reasons. Scans were carried out by one of four experienced radiographers. All structural abnormalities of the renal tract were reported, and dilatation of the renal pelvis of $1 \mathrm{~cm}$ or more was considered important. ${ }^{7}$ Senior paediatric staff were available to discuss the implications of suspected abnormality with the parents.

Babies in whom an abnormality had been detected antenatally were scanned at the end of the first week. When this confirmed an abnormality contrast radiography (micturating cystourethrography and intravenous pyelography) and isotope scanning if indicated were performed. Antibiotics were given prophylactically to all of these babies from birth until the diagnosis was established.

Over 12 months 6292 scans at around 28 weeks' gestation were obtained. Fifty six women registered too late or not at all, and 12 did not attend at 28 weeks; thus the uptake of the screening programme was $99 \%$. This population of 6360 mothers delivered 6425 babies. There were no referrals from outside the district for renal abnormalities. No pregnancy was terminated because of renal disease, and no fetus received intrauterine surgical intervention.

Children with a renal abnormality that had been missed antenatally were identified from the radiological records of renal investigations. In this district such investigations in children are usually carried out in one department by the same consultant radiologist (JAE). All intravenous pyelograms, micturating cystograms, and renal ultrasound scans obtained in children born between November 1986 and January 1988 (corresponding to our study population) were examined. For children with an abnormality that had not been identified by antenatal scanning the maternal records were also examined. Maximum follow up was 18 months.

\section{Results}

Table I gives the incidence of suspected and confirmed renal abnormalities in the study population. Ninety two $(1.4 \%)$ antenatal scans were abnormal.

Forty two babies $(46 \%$ of those with abnormal 
antenatal scans) had an important abnormality of the renal tract confirmed postnatally, giving an incidence of $0.65 \%$. Of these, 13 had bilateral disease. The antenatal scan correctly predicted whether the lesion was unilateral or bilateral in 35 babies. Twenty of the confirmed abnormalities were due to obstructive lesions. Only two of the babies had vesicoureteric reflux. Table II gives the diagnosis and outcome for these 42 babies.

At follow up 18 babies had had an operation, most of them within the first few months. A further three were awaiting an operation. Therefore, of the 38 babies in whom an abnormality was confirmed postnatally and who survived, 21 had had or were soon going to have an operation. The two babies with reflux were receiving chemoprophylaxis, and neither had had a urinary tract infection. Seven babies had persistent mild dilatation. This was defined as dilatation of the renal pelvis to a length of $2 \mathrm{~cm}$ or more with no caliceal abnormality at four to six months and no evidence of reflux or pelviureteric obstruction on contrast radiography.

Of the 92 babies with suspected abnormal antenatal scans, 37 had normal renal tracts in two postnatal scans (one obtained in the neonatal period and one at 4 to 6 months of age). These babies were discharged from further follow up. In 10 babies extrarenal pelvis was diagnosed postnatally on ultrasonography. None of these babies subsequently presented with illness related to the renal tract. Three babies failed repeatedly to attend for a postnatal scan and were lost to follow up.

Five deaths occurred: two babies with bilateral polycystic kidneys died in the neonatal period, as did one baby with posterior urethral valves and lung hypoplasia. The baby with bilateral renal agenesis had the caudal dysplasia syndrome and died soon after birth. One baby who had normal kidneys on postnatal ultrasonography died of congenital myotonic dystrophy; this disease may have predisposed him to renal dilatation in utero.

Seven babies had an abnormality of the renal tract that had not been identified antenatally. All of these patients presented with urinary tract infection, five of

TABLE I-Outcome of antenatal ultrasonography

\begin{tabular}{lc}
\hline & $\begin{array}{c}\text { No } \\
(n=6360)\end{array}$ \\
\hline Scans at 28 weeks' gestation & 6292 \\
Abnormal antenatal scans & 92 \\
Confirmed renal abnormalities & 42 \\
Total renal abnormalities diagnosed by 18 months' follow up & 49
\end{tabular}

TABLE II-Diagnosis and outcome at 18 months for 42 babies. Number with renal abnormalities that were confirmed postnatally (and number of deaths)

\begin{tabular}{|c|c|c|c|}
\hline Diagnosis & $\begin{array}{l}\text { No of } \\
\text { cases }\end{array}$ & $\begin{array}{c}\text { No with } \\
\text { bilateral } \\
\text { abnormalities }\end{array}$ & $\begin{array}{c}\text { No who had } \\
\text { had or were } \\
\text { awaiting an } \\
\text { operation }\end{array}$ \\
\hline Obstruction of pelviureteric junction & 12 & 2 & 9 \\
\hline Urethral valves & 2 & $2(1)$ & 1 \\
\hline $\begin{array}{l}\text { Obstructed ureter, megaloureter, } \\
\text { ureterocele }\end{array}$ & 4 & 1 & 4 \\
\hline Obstructed duplex system & 2 & & \\
\hline $\begin{array}{l}\text { Dysplastic or polycystic kidney, or } \\
\text { both }\end{array}$ & 10 & $2(2)$ & 5 \\
\hline Vesicoureteric reflux & 2 & 2 & \\
\hline $\begin{array}{l}\text { Persistent mild dilatation of renal } \\
\text { pelvis }{ }^{\star}\end{array}$ & 7 & 2 & \\
\hline Persistent urachus & 1 & & 1 \\
\hline $\begin{array}{l}\text { Persistent cloaca and hypertrophied } \\
\text { bladder }\end{array}$ & 1 & 1 & 1 \\
\hline Renal agenesis & 1 & $1(1)$ & \\
\hline Total & 42 & $13(4)$ & 21 \\
\hline
\end{tabular}

$\star$ Dilatation to a length $\geqslant 2 \mathrm{~cm}$ with no caliceal abnormality at four to six months and no evidence of reflux or pelviureteric obstruction on contrast radiography.
TABLE III-Diagnosis and outcome for seven babies with renal abnormalities not detected by antenatal ultrasonography

\begin{tabular}{lclc}
\hline Diagnosis & $\begin{array}{c}\text { No of } \\
\text { cases }\end{array}$ & $\begin{array}{c}\text { Scans performed } \\
\text { antenatally }\end{array}$ & $\begin{array}{c}\text { Operation } \\
\text { performed }\end{array}$ \\
\hline Reflux & 4 & $\begin{array}{c}\text { None (1 patient) ultrasound } \\
\text { at 28 weeks (3 patients) }\end{array}$ & No \\
Duplex system with reflux & 1 & $\begin{array}{c}\text { Ultrasound at 26 and 34 } \\
\text { weeks }\end{array}$ & No \\
$\begin{array}{l}\text { Megaloureter } \\
\begin{array}{l}\text { Obstruction of } \\
\text { pelviureteric junction }\end{array}\end{array}$ & 1 & $\begin{array}{l}\text { Ultrasound at 28 weeks } \\
\text { Ultrasound at 25 and 35 } \\
\text { weeks }\end{array}$ & $\begin{array}{c}\text { Yes } \\
\text { Yes }\end{array}$ \\
\hline
\end{tabular}

them at 3 months of age or less and the remaining two at 7 and 8 months. Table III gives the diagnoses and outcomes. Thus a total of 49 babies with abnormalities of the renal tract were identified, giving an incidence of $0.76 \%$.

In this study antenatal ultrasonography at 28 weeks as a screening test showed a specificity of $99 \%(6200 /$ $6247)$ and a sensitivity of $88 \%(42 / 48)$. These figures are estimates as the true incidence of false negative results could not be known with only 18 months' follow up; renal disease may become apparent at a later stage.

\section{Discussion}

This was a prospective population study using antenatal ultrasonography at a specific time in pregnancy to screen for abnormalities of the renal tract. By looking at abnormalities diagnosed antenatally and those discovered postnatally within the same population we estimated the incidence of renal abnormality. The overall incidence was $0.76 \%$, which is much higher than reported previously. ${ }^{4589}$ This may be because a high proportion of the population in our study had ultrasound scans and all the scans were obtained at the same stage of pregnancy. The proportion of patients requiring an operation was comparable with results of other studies. ${ }^{23}$

We assessed the importance of antenatal diagnosis in terms of definite or probable benefit. If we assume that all babies requiring intervention - that is, an operation or chemoprophylaxis-benefited then $55 \%$ (23/42) benefited from early diagnosis. This is a higher proportion than that quoted by other workers. ${ }^{18}$ Probable benefit is difficult to assess because the natural course and implications of pelviureteric obstruction and unilateral dysplastic kidney are uncertain. Antenatal diagnosis of some obstructive lesions not requiring an operation, however, would probably prevent urinary tract infection and allow early identification of progression. Those patients with unilateral dysplastic kidney who were not operated on were followed up with regard to hypertension. Therefore a further eight patients probably benefited (19\% of those with a confirmed abnormality).

Seven babies had mild renal tract dilatation. Follow up was continued for those but the early identification of this condition was of doubtful benefit. Their outcome was likely to be favourable, and long term follow up may not be indicated for this group.

About half of all of the suspected abnormalities were false positive results. The stress caused to parents by the diagnosis of an abnormality in utero should be remembered, and the importance of counselling by appropriate staff has been emphasised previously. ${ }^{810}$ Improvement in techniques and skill may help to reduce the rate of false positive results: one other screening programme reported no false positive results. ${ }^{5}$ Some of the babies with abnormal antenatal scans may have had vesicoureteric reflux, but this would have been missed because we decided not to obtain micturating cystograms if the postnatal scan was normal on two occasions. None of the babies with two normal postnatal scans had any evidence of infection. 
Seven renal abnormalities were diagnosed that had not been detected antenatally. Only one of the seven mothers had not attended for any scans; in the others the abnormality had not been found in appropriate scans. Four of these patients had vesicoureteric reflux, which is known to be difficult to diagnose antenatally. ${ }^{4}$

The impact that early diagnosis of abnormalities of the fetal renal tract and subsequent intervention may have on the incidence of symptomatic renal disease later in life-for example, acute pyelonephritis and recurrent urinary tract infection-remains unknown. We also do not know what proportion of those in whom a renal abnormality was diagnosed antenatally would have suffered renal scarring or deterioration of renal function had the diagnosis been delayed until after a urinary tract infection. To obtain this information would require an untreated control group, which would not be ethical. We intend, however, to reassess this cohort of children at age 5 years to determine the incidence of renal disease.

We found a high incidence of renal abnormalities in this study and conclude that antenatal ultrasonography at 28 weeks' gestation is an effective method of screening for structural renal abnormality.

We thank Dr S A Price and the staff of the ultrasonography department for their help in collecting data.

Turnock RR, Shawis R. Management of fetal urinary tract abnormalities detected by prenatal ultrasonography. Arch Dis Child 1984;59:962-5.

Smith D, Egginton JA, Brookfield DSK. Detection of abnormality of feta urinary tract as a predictor of renal tract disease. Br Med $\mathcal{F} 1987 ; 294: 27-8$.

Madarikan BA, Hayward C, Roberts GM, Lari J. Clinical outcome of feta uropathy. Arch Dis Child 1988;63:961-3.

Ring E, Zobel G. Urinary infection and malformations of urinary tract in infancy. Arch Dis Child 1988;63:818-20."

Helin I, Persson P-H. Prenatal diagnosis of urinary tract abnormalities by ultrasound. Pediatrics 1986;78:879-83.

6 Pocock RD, Witcombe JB, Andrews HS, Berry PJ, Frank JD. The outcome of antenatally diagnosed urological abnormalities. Br f Urol 1985;57:788-92. antenatally diagnosed urological abnormalities. $B r \mathcal{F}$ Urol $1985 ; 57: 788-92$.
Grignon A, Filion R, Filiatrault $\mathrm{D}$, et al. Urinary tract dilatation in utero: Grignon A, Filion R, Filiatrault D, et al. Urinary tract dilatation
classification and clinical applications. Radiology 1986;160:645-7.

classification and clinical applications. Radiology 1986;160:645-7.
Watson AR, Readett D, Nelson CS, Kapila L, Mayell MJ. Dilemmas associated with antenatally detected urinary tract abnormality. Arch $D i$ Child 1988;63:719-22.

Thomas DFM, Irving HC, Arthur RJ. Pre-natal diagnosis: how useful is it? Brf Urol 1985;57:784-7.

10 Furness ME. Reporting obstetric ultrasound. Lancet 1987;i:675-6.

(Accepted 9 March 1989)

\title{
Clinical and laboratory studies of arthritis in leprosy
}

\author{
S L Atkin, A El-Ghobarey, M Kamel, J P Owen, W C Dick
}

\begin{abstract}
Arthritis associated with leprosy is underreported. In Egypt 66 patients from a leprosy colony were studied, 20 of whom had arthropathy. This was characterised by an inflammatory symmetrical peripheral polyarthritis. The wrist, metacarpal and proximal interphalangeal joints of the hands, the knees, and the metatarsophalangeal joints of the feet were affected with associated morning stiffness. The arthritis was erosive in 11 out of 20 patients, had no features of the arthritis associated with erythema nodosum leprosum reactions, but symptomatically responded to antileprosy treatment.

This arthritis would seem to be a previously unrecognised feature of leprosy.
\end{abstract}

\section{Introduction}

Leprosy is caused by the obligate intracellular parasite Mycobacterium leprae.' Considerable attention has been devoted to the dermal, neural, and osseous complications of leprosy ${ }^{2}$ but little to those of the synovial joint, apart from the arthritis associated with erythema nodosum leprosum ${ }^{3.5}$ and the well recognised Charcot's joint. In two large scale studies from India musculoskeletal problems were found in some patients with leprosy, but no detailed information was given. ${ }^{67}$ We have reported a peripheral, deforming polyarthritis in patients with leprosy in the absence of erythema nodosum leprosum in Papua New Guinea, but no radiological examinations or follow up were performed. ${ }^{8}$

We examined patients with active leprosy in Egypt, putting particular emphasis on the clinical and radiological features of the synovial joints.

\section{Abou Zabel Leprosy}

Colony, Kaloubya, Egypt A El-Ghobarey, MRCP, professor of rheumatology

$M$ Kamel, MD, professor of

haematology and immunology

Correspondence to: $\mathrm{Dr}$ Dick.

BrMed f 1989;298:1423-5
All patients from the Abou Zabel leprosy colony in Egypt attending the medical clinic to receive supplies of their antileprosy treatment were asked to participate in this study. Sixty six consecutive volunteers (44 men and 22 women; mean (SE) age $34 \cdot 3(15 \cdot 4)$ years; mean duration of the disease $8.5(2 \cdot 8)$ years) participated in the study and all gave informed consent. Patients with Charcot's arthropathy or any clinical neurological abnormality were excluded. The diagnosis of leprosy was confirmed in each case from skin smears and biopsy specimens and classified according to the method of Ridley and Jopling.

A detailed history was taken of peripheral articular disease, particular attention being paid to a personal or family history of any of the codiseases of seronegative spondarthritides. ${ }^{9}$ Any history of stiffness or pain was graded and a functional index of musculoskeletal impairment completed. ${ }^{10}$ The pattern of development of the articular symptoms was plotted, and in all patients the Ritchie articular index was scored." Haemoglobin concentration, white cell count, and erythrocyte sedimentation rate were measured at the clinical examination. The history and examination, microscopy of urine and stools, and rectal biopsy were used to exclude schistosomiasis and infection with yersinia and Gram negative enteropathic bacteria. Hepatitis B and syphilis were excluded serologically.

Patients with lepromatous leprosy were initially treated with rifampicin (600 $\mathrm{mg}$ once daily) and clofazimine ( $100 \mathrm{mg}$ once daily) for four weeks followed by dapsone ( $100 \mathrm{mg}$ once daily) and clofazimine (100 $\mathrm{mg}$ thrice weekly) for life thereafter; patients with borderline and borderline lepromatous leprosy were treated with rifampicin (600 $\mathrm{mg}$ once daily) and clofazimine (100 mg once daily) for one week and dapsone (100 mg once daily) for life thereafter; and patients with borderline tuberculoid and tuberculoid leprosy were treated with only dapsone (100 mg once daily) for two years.

Standard radiographs were taken of the hands, feet, and knees and were assessed by one radiologist (JPO), who did not know the clinical and laboratory results. Only those patients with arthritis underwent radiography. Serum was separated and aliquots were transported to England in dry ice. IgM rheumatoid factor, ${ }^{12}$ $\alpha_{1}$ acid glycoprotein, $\alpha_{2}$ macroglobulin, ${ }^{13}$ and $C$ reactive protein ${ }^{14}$ concentrations were determined by established methods. 